Eur. J. Clin. Chem. Clin. Biochem.

Vol. 31, 1993, pp. 317-322

(C) 1993 Walter de Gruyter \& Co.

Berlin $\cdot$ New York

\title{
The Use of Liquid Chromatography-Mass Spectrometry for the Identification and Quantification of Urinary Iminodipeptides in Prolidase Deficiency
}

\author{
By Kazunori Sugahara, ${ }^{1}$ Takashi Ohno, ${ }^{2}$ Jiro Arata ${ }^{2}$ and Hiroyuki Kodama ${ }^{1}$ \\ ${ }^{1}$ Department of Chemistry, Kochi Medical School, Kochi, Japan \\ ${ }^{2}$ Department of Dermatology, Okayama University Medical School, Okayama, Japan
}

(Received April 13/August 11, 1992)

\begin{abstract}
Summary: It has been reported that the urine of patients with prolidase deficiency contains various iminodipeptides with a carboxyl-terminal proline (hydroxyproline). These iminodipeptides have hitherto been detected indirectly by acid hydrolysis or enzymatic digestion, followed by amino acid analysis. In the present study, it was shown that X-Pro could be distinguished from Pro-X when the iminodipeptides were analysed directly by liquid chromatography coupled with atmospheric pressure ionization mass spectrometry (LC/API-MS), with scanning of the protonated molecule ions $\left([\mathrm{M}+\mathrm{H}]^{+}\right)$. The same procedure also successfully quantified urinary iminodipeptides from patients with prolidase deficiency. A quantitative investigation of two siblings with prolidase deficiency revealed that the patient with severe clinical symptoms excreted more iminodipeptides than the other who did not have serious symptoms. LC/API-MS also revealed iminodipeptides (Gly-Hyp and Pro-Hyp) in the urine of the mother of the patients and in normal volunteers. Patients excreted much more Pro-Hyp than normal volunteers, whereas no quantitative differences were found between the mother and controls. In patients, the excretion of large quantities of X-Pro is due to their very low prolidase activity towards this type of substrate. In the erythrocytes of patients, prolidase activity towards X-Hyp was extremely low; even in the mother and normal volunteers, it was remarkably low in comparison with the activity against X-Pro.
\end{abstract}

\section{Introduction}

Prolidase (EC 3.4.13.9) ${ }^{1}$ ) is expressed in all human tissues, and it catalyses the hydrolysis of iminodipeptides with a C-terminal prolyl residue. Prolidase deficiency $(1-5)$ is a rare autosomal recessive disease affecting collagen metabolism, characterized by chronic ulcerative dermatitis and mental retardation. It has been reported that patients with prolidase deficiency, initially named iminopeptiduria, excrete large amounts of iminodipeptides containing a C-terminal proline or hydroxyproline in the urine $(6,7)$. Urinary iminodipeptides have been identified by analysis of ') Enzyme: Prolidase (peptidase D, imidodipeptidase, EC
3.4.13.9) the amino acids liberated by acid hydrolysis or enzymatic digestion, using an amino acid analyser (3, $6,7)$ or isotachophoresis $(8)$. These methods gave only indirect qualitative analyses, and an exact identification and quantification have never been reported.

High performance liquid chromatography (HPLC) is one of the most effective means of separating peptide mixtures (9) and HPLC connected to atmospheric pressure ionization mass spectrometry (LC/API-MS) has recently attracted considerable attention as a new analytical method in various fields $(10,17)$. In contrast to gas chromatography-mass spectrometry, samples do not need to be derivatized for LC/API-MS, which can rapidly analyse even substances easily af- 
fected by heat. This procedure shows promise for the analyses of compounds in biological samples. A previous paper (11) reported that LC/API-MS could directly detect various synthetic and urinary iminodipeptides by scanning the protonated molecule ions $\left([\mathrm{M}+\mathrm{H}]^{+}\right)$. In the present study it was investigated whether authentic iminodipeptides containing a Cterminal proline could be distinguished from those containing an N-terminal proline, using LC/API-MS. The procedure was also used for the quantitative analyses of the urinary iminodipeptides in prolidase deficiency. Urine samples from the mother of affected patients and from normal volunteers were also scanned for iminodipeptides.

It was discovered by Powell et al. that iminopeptiduria was the result of an enzyme defect, and that prolidase deficiency could be diagnosed by the assay of prolidase activity in erythrocytes, leukocytes and cultured skin fibroblasts. Furthermore, two isozymes of prolidase (prolidase I and II) in normal humans have been studied. Prolidase I has a relative molecular mass of about 112000 and the highest activity towards GlyPro, whereas prolidase II has a relative molecular mass of about 185000 and is mainly active towards Met-Pro. Characteristics of the isozymes in patients and controls have been discussed in detail (12-16). The present paper also reports the prolidase activities for X-Hyp in patients, in their mother and in controls, which are closely correlated with the quantities of XHyp excreted in the urine.

\section{Materials and Methods}

\section{Reagents}

Synthetic iminodipeptides containing a C-terminal proline or hydroxyproline (Gly-Pro, Ala-Pro, Val-Pro, Leu-Pro, Pro-Pro, Ser-Pro, Gly-Hyp and Pro-Hyp) and iminodipeptides containing an N-terminal proline (Pro-Gly, Pro-Ala and Pro-Leu) were purchased from Sigma Chemical Company (St. Louis, MO, USA). The protein assay kit was from Pierce (Rockford, IL, USA), and the urinary creatinine assay kit was from Wako Pure Chemical Industries Ltd. (Osaka, Japan). All other chemicals were of analytical grade.

\section{Apparatus}

A Hitachi L-6200 high-performance liquid chromatograph (HPLC) was connected to a Hitachi M-80B double-focussing mass spectrometer through an atomospheric pressure ionization interface $(11,17)$. LC/API-MS data were obtained with a Hitachi M-0101 data acquisition system. Qualitative and quantitative analyses of a variety of iminodipeptides were carried out under the following conditions. Inertsil ODS reverse-phase packed columns $(4.6 \mathrm{~mm}$ ID $\times 150 \mathrm{~mm}$ or $4.6 \mathrm{~mm}$ ID $\times 250$ $\mathrm{mm}$ ) from Gasukuro Kogyo Ltd. (Tokyo, Japan) were used for the HPLC. Trifluoroacetic acid $(1 \mathrm{~g} / \mathrm{l})$ : methanol $(75+25$, by vol.) was used as the mobile phase at a flow rate of $0.9 \mathrm{ml} /$ min. Nebulizer temperature, desolvator temperature and drift voltage were $255^{\circ} \mathrm{C}, 390^{\circ} \mathrm{C}$ and $225 \mathrm{~V}$, respectively.

\section{Samples}

Blood was taken from two patients (sisters) with prolidase deficiency, from their mother and from controls (laboratory personnel) into heparinized tubes. The erythrocytes were isolated by Umemura's method (4) and stored at $-80^{\circ} \mathrm{C}$ until use. Urine samples from patients, their mother and controls were taken into bottles containing a small amount of $2 \mathrm{~mol} / \mathrm{l}$ hydrochloric acid and toluene, and kept at $=20^{\circ} \mathrm{C}$ until use.

\section{Isolation of iminodipeptides from urine}

Urine samples $(3 \mathrm{ml})$ from the two patients, their mother and normal volunteers were weakly acidified with $2 \mathrm{~mol} / \mathrm{l}$ acetic acid and filtered. The filtrate was transferred to a column $(0.9 \times 20$ $\mathrm{cm}$ ) containing a cation-exchange resin (Diaion SK-1, H-form, $100 \sim 200$ mesh, Mitsubishi Kasei Kogyo Ltd., Tokyo, Japan), washed with $30 \mathrm{ml}$ of water, and eluted with $30 \mathrm{ml}$ of $2 \mathrm{~mol} / 1$ ammonia. The eluate was evaporated to dryness under reduced pressure. The residue was dissolved in $1 \mathrm{ml}$ of water, then subjected to LC/API-MS. The creatinine concentration in each urine sample was determined using the kit described above.

\section{Assay of prolidase activity}

Erythrocyte lysates were prepared from the heparinized blood of patients and normal volunteers according to Umemura's method (4). A mixture containing $10 \mu \mathrm{l}$ of diluted erythrocyte lysates, $10 \mu \mathrm{l}$ of $10 \mathrm{mmol} / 1 \mathrm{MnCl}_{2}$ and $80 \mu \mathrm{l}$ of $50 \mathrm{mmol} / \mathrm{l}$ Tris$\mathrm{HCl}\left(\mathrm{pH} \mathrm{7.8)}\right.$ was preincubated for $10 \mathrm{~min}$ at $37^{\circ} \mathrm{C}$, then incubated with $100 \mu \mathrm{l}$ of $10 \mathrm{mmol} / \mathrm{l}$ substrate (X-Pro) in $1 \mathrm{mmol} / 1 \mathrm{MnCl}_{2}$ for $30 \mathrm{~min}$ at $37^{\circ} \mathrm{C}$. The reaction was terminated by the addition of $200 \mu \mathrm{l}$ of $100 \mathrm{~g} / \mathrm{l}$ trichloroacetic acid solution. After $10 \mathrm{~min}$ at $90^{\circ} \mathrm{C}$ with Chinard's reagent (18) which consisted of ninhydrin, phosphoric acid and acetic acid, liberated proline was estimated by spectrophotometry (wavelength: $515 \mathrm{~nm}$ ). The activity towards X-Hyp was assayed similarly, but after the addition of trichloroacetic acid was centrifuged at $3000 \mathrm{~min}^{-1}$ for $5 \mathrm{~min}$. Supernatant $(0.5 \mathrm{ml})$ was then incubated with $2.5 \mathrm{~g} / 1$ copper sulphate, $100 \mathrm{~g} / \mathrm{l}$ sodium hydroxide and $1.8 \mathrm{~mol} / 1$ hydrogen peroxide $(0.5 \mathrm{ml}$ of each) for $5 \mathrm{~min}$ at room temperature, then for $5 \mathrm{~min}$ at $80^{\circ} \mathrm{C}$. After cooling the mixture to $0^{\circ} \mathrm{C}, 2 \mathrm{ml}$ of $0.75 \mathrm{~mol} / \mathrm{l}$ sulphuric acid and $1 \mathrm{ml}$ of $50 \mathrm{~g} / \mathrm{l} p$-dimethyl-aminobenzaldehyde were added and the mixture was incubated for $10 \mathrm{~min}$ at $70^{\circ} \mathrm{C}$. The absorbance of the solution was measured at $575 \mathrm{~nm}$.

\section{Results}

The sensitive detection of authentic iminodipeptides containing $\mathrm{C}$-terminal proline by scanning their protonated molecule ions $\left([\mathrm{M}+\mathrm{H}]^{+}\right)$by LC/API-MS has been reported previously (11). There are two types of iminodipeptide, i.e. with a C-terminal or an $\mathrm{N}$ terminal proline. Thus we determined whether LC/ API-MS could distinguish iminodipeptides containing a C-terminal from those containing an N-terminal proline. The iminodipeptide pairs Pro-Gly/Gly-Pro, Pro-Ala/Ala-Pro and Pro-Leu/Leu-Pro have the same protonated molecule mass (m/e) of 173, 187 and 229 respectively. The mass chromatograms and mass spectra of these pairs are presented in figure 1. The two peaks of each pair were clearly separated, showing the difference of retention time on mass chromatograms. Pro-Gly and Pro-Ala were eluted earlier than 

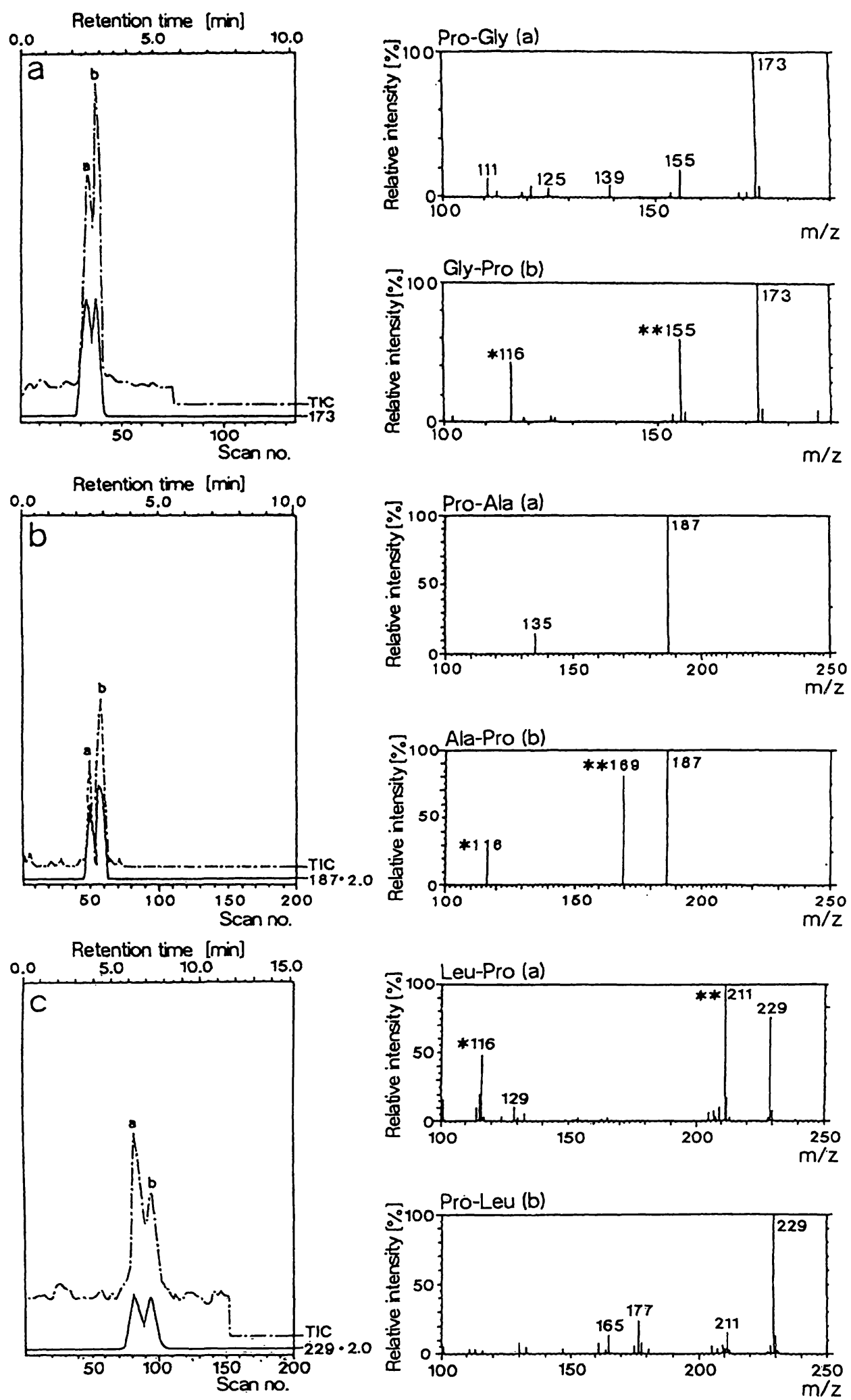

Fig. 1. Mass chromatograms and mass spectra of a mixture of authentic Pro-Gly and Gly-Pro (a-(a),(b): $\left.M_{\mathrm{r}} 172\right)$, Pro-Ala and Ala-Pro (b-(a),(b): $M_{\mathrm{r}}$ 186), Leu-Pro and Pro-Leu (C-(a),(b): $\left.M_{\mathrm{r}} 228\right) .^{*}$ and ${ }^{* *}$ in the mass spectra indicate the proline residue $+2 \mathrm{H}$ ions and $[\mathrm{M}+\mathrm{H}]^{+}-\mathrm{H}_{2} \mathrm{O}$ ions, respectively. TIC stands for total ion chromatogram. These analyses were carried out over a mass range of 0 to 500 , with a scan rate of $4.0 \mathrm{~s}$.

Gly-Pro and Ala-Pro, respectively, whereas Pro-Leu was eluted later than Leu-Pro. For example, comparison of the mass spectra of Pro-Gly and Gly-Pro shows that only Gly-Pro produces appreciable quantities of both the $[\mathrm{M}+\mathrm{H}]^{+}-\mathrm{H}_{2} \mathrm{O}$ ion** $(\mathrm{m} / \mathrm{z}: 155)$ and the proline residue $+2 \mathrm{H}$ ion* $(\mathrm{m} / \mathrm{z}: 116)$, in addition to the base peak ion $[\mathrm{M}+\mathrm{H}]^{+}$. Ala-Pro and Leu-Pro also formed an $\left[\mathrm{M}+\mathrm{H}^{+}-\mathrm{H}_{2} \mathrm{O}\right.$ ion** and the proline residue $+2 \mathrm{H}$ ion* (fig. 1). The previous report (11) showed the peaks produced by various 
urinary iminodipeptides from a patient with prolidase deficiency. On the basis of the present study, it now seems certain that those urinary iminodipeptides contained a $\mathrm{C}$-terminal proline.

Good correlations were obtained between the concentrations of synthetic iminodipeptides and the peak areas on mass chromatograms, so that the calibration curves were linear (fig. 2). Quantification of some standard iminodipeptides applied to the cation-exchange columns demonstrated approximately $95 \%$ recovery, and standards added to normal urine also showed a recovery of $90 \sim 95 \%$ (data not shown). Urine samples from patients with prolidase deficiency were passed through the column, and the effluent was monitored for selected ions (selected ion monitoring,

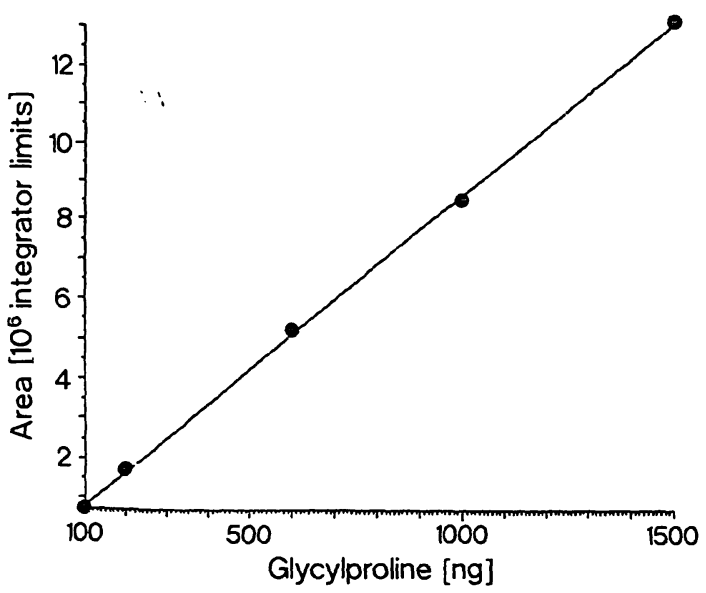

Fig. 2. The calibration curve for Gly-Pro, showing concentrations plotted against peak areas. The analyses were performed over a mass range of 0 to 1500 , with a scan rate of $128.0 \mathrm{~s}$. The lower detection limit $100 \mathrm{ng}$ for Gly-Pro by LC/API-MS represents the highest sensitivity observed in these assays.

$\begin{array}{ll}\text { Slope: } & 8.698 \cdot 10^{3} \\ \text { Intercept: } & -2.715 \cdot 10^{4} \\ \mathrm{~s}_{\mathrm{x}}: & 1.040 \cdot 10^{1} \\ \mathrm{~s}_{\mathrm{y}}: & 9.050 \cdot 10^{4} \\ \mathrm{r}: & 0.997\end{array}$

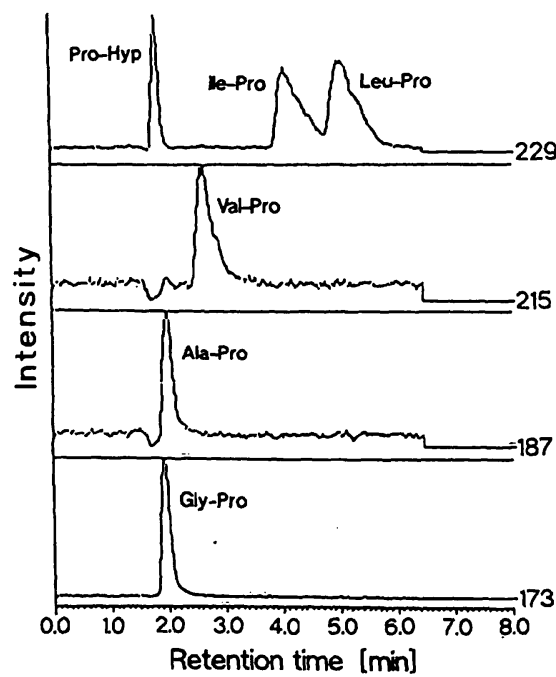

SIM). The resulting chromatogram showed clear peaks of iminodipeptides with no interference from other peaks (fig. 3). Quantification of X-Pro based on peak areas is shown in table 1-A. Gly-Hyp $\left([\mathrm{M}+\mathrm{H}]^{+}: 189\right)$ and Pro-Hyp ${ }^{\prime}\left([\mathrm{M}+\mathrm{H}]^{+}: 229\right)$ are excreted in the urine of a patient with prolidase deficiency (11). However, scans of the urine sample from the patients' mother and samples from normal volunteers at $[\mathrm{M}+\mathrm{H}]^{+} 189$ and 229 , revealed clear peaks corresponding to Gly-Hyp and Pro-Hyp on SIM chromatograms (fig. 4). The levels of urinary Gly-Hyp and Pro-Hyp in siblings with prolidase deficiency, their mother and normal volunteers were determined by LC/API-MS and the results are presented in table 1-B. Although little difference was found between patients and normal volunteers with

Tab. 1 (A). Amounts of iminodipeptides (X-Pro) in the urines of patients, their mother and a control $(\mu \mathrm{g} / \mathrm{mg}$ creatinine)

\begin{tabular}{lllll}
\hline & $\begin{array}{l}\text { Patient A } \\
\text { (elder) }\end{array}$ & \multicolumn{1}{l}{$\begin{array}{l}\text { Patient B } \\
\text { (younger) }\end{array}$} & Mother Control \\
\hline Gly-Pro & $899.2 \pm 123.5$ & $722.4 \pm 168.8$ & ND & ND \\
Ala-Pro & $113.7 \pm 13.9$ & $74.8 \pm 15.3$ & ND & ND \\
Val-Pro & $167.9 \pm 28.0$ & $120.4 \pm 58.4$ & ND & ND \\
Leu-Pro & $355.3 \pm 70.0$ & $249.6 \pm 104.7$ & ND & ND \\
lle-Pro & $309.6 \pm 46.4$ & $231.4 \pm 97.0$ & ND & ND \\
Ser-Pro & $317.6 \pm 62.2$ & $207.0 \pm 70.4$ & ND & ND \\
Pro-Pro & $670.8 \pm 139.5$ & $589.3 \pm 285.2$ & ND & ND \\
Met-Pro & ND & ND & ND & ND \\
\hline
\end{tabular}

mean $\pm \mathrm{SD}(\dot{\mathrm{n}}=5), \mathrm{ND}:$ not detectable

Tab. 1 (B). Amounts of iminodipeptides (X-Hyp) in the urines of patients, their mother and controls $(\mu \mathrm{g} / \mathrm{mg}$ creatinine)

\begin{tabular}{lrrll}
\hline & $\begin{array}{l}\text { Patient A } \\
\text { (elder) }\end{array}$ & $\begin{array}{l}\text { Patient B } \\
\text { (younger) }\end{array}$ & Mother & Control \\
\hline Gly-Hyp & $3.7 \pm 1.6$ & $4.5 \pm 1.7$ & $4.1 \pm 0.1$ & $3.8 \pm 2.7$ \\
Pro-Hyp & $59.7 \pm 20.9$ & $52.4 \pm 8.7$ & $6.1 \pm 2.1$ & $9.3 \pm 6.0$ \\
\hline
\end{tabular}

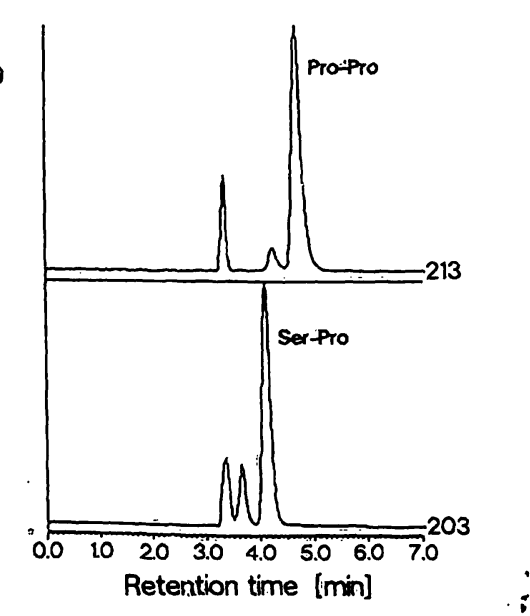

Fig. 3. SIM chromatograms of various iminodipeptides in the urine sample of a patient with prolidase deficiency. The mass spectrometric conditions were the same as those described in fig. 2. 


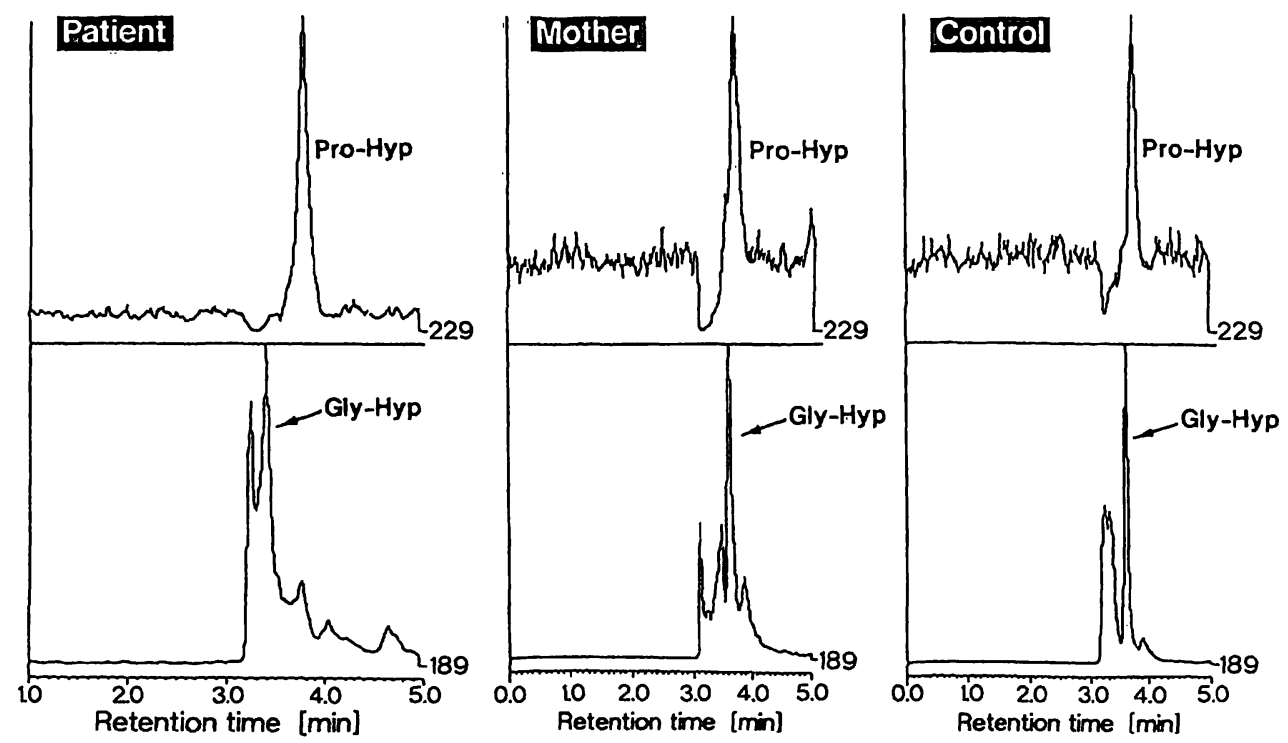

Fig. 4. SIM chromatograms of Gly-Hyp $\left([\mathrm{M}+\mathrm{H}]^{+}: 189\right.$, arrows $)$ and Pro-Hyp $\left([\mathrm{M}+\mathrm{H}]^{+}: 229\right)$ in the urines of a patient with prolidase deficiency, her mother and a normal volunteer. The mass spectrometric conditions were the same as those described in fig. 2.

respect to Gly-Hyp, patients excreted much more ProHyp than either their mother or normal volunteers. No differences in Gly-Hyp or Pro-Hyp excretion were found between normal volunteers and the patients' mother, who was heterozygous for the prolidase gene (19).

As enzymatic activity and excretion of iminodipeptides in the urine are closely related, prolidase activity, particularly towards X-Hyp, is worthy of note. Therefore prolidase activities against $\mathrm{X} \div$ Pro and $\mathrm{X}-\mathrm{Hyp}$ in erythrocytes from patients, the mother and normal volunteers were determined by the method described under Materials and Methods. The prolidase activities of patients towards Gly-Pro and Pro-Pro were very low compared with controls, and the mother had approximately half as much activity as normal volunteers, which agreed with a previous report (19). The prolidase activities of patients towards Gly-Hyp and Pro-Hyp were much lower than those towards GlyPro and Pro-Pro. It was also found that even in normal volunteers, prolidase activities towards GlyHyp and Pro-Hyp are extremely low, and that the prolidase activities of the patients' mother towards both X-Hyp and X-Pro are about one half of the control values (tab. 2).

Tab. 2. Prolidase activities towards Gly-Pro, Gly-Hyp, Pro-Pro and Pro-Hyp in the erythrocytes of patients, their mother and controls (nmol/min $\cdot \mathrm{mg}$ protein)

\begin{tabular}{llllr}
\hline & $\begin{array}{l}\text { Patient A } \\
\text { (elder) }\end{array}$ & $\begin{array}{l}\text { Patient B } \\
\text { (younger) }\end{array}$ & Mother & Control \\
\hline Gly-Pro & 1.074 & 1.258 & 7.755 & $12.253 \pm 1.686$ \\
Gly-Hyp & 0.008 & 0.005 & 0.078 & $0.118 \pm 0.012$ \\
Pro-Pro & 0.361 & 0.320 & 1.511 & $2.384 \pm 0.259$ \\
Pro-Hyp & 0.004 & ND & 0.047 & $0.069 \pm 0.009$ \\
\hline
\end{tabular}

mean $\pm S D(n=5), N D:$ not detectable

\section{Discussion}

Previously used procedures employing acid hydrolysis or enzymatic digestion, followed by amino acid analysis, were unable to directly identify and quantify iminodipeptides containing a $\mathrm{C}$-terminal proline or hydroxyproline in the urine of patients with hereditary prolidase deficiency. However, the LC/API-MS system used in this study distinguished between X-Pro and Pro- $X$ on a mass chromatogram and mass spectrum, and is therefore suitable for the exact identification of urinary iminodipeptides. This apparatus, moreover, performed rapid simultaneous quantitative analyses of several iminodipeptides. Quantification of urinary iminodipeptides (X-Pro) revealed that a patient with severe dermatitis excreted more iminodipeptides than her younger sibling with few clinical symptoms. Collagen metabolism can be closely related to inflammation, and it may be reflected in the excretion of iminodipeptides in urine. Human prolidase consists of two isozymes (prolidase I and II) which are different in substrate specificity and in some biochemical characteristics. Prolidase deficiency involves a complete deficiency of prolidase $I$, which shows the highest activity towards Gly-Pro. Prolidase II, which is active mainly against Met-Pro, shows the same activity in patients as in normal controls. Complete digestion of Met-Pro by prolidase II seems to be the reason why Met-Pro cannot be detected at all in urine samples from patients (tab. 1).

The present investigations revealed that not only the patients but also their mother and normal volunteers excreted Gly-Hyp and Pro-Hyp into the urine. The patients excreted more Pro-Hyp than either their mother or controls. There was little difference between the excretion of Gly-Hyp by patients and controls, 
and this may reflect the limited production of GlyHyp from collagen, which contains far more Pro-Hyp than Gly-Hyp. Furthermore, there was no quantitative difference between the X-Hyp excretion of mother and controls (tab. 1-B). This interesting finding is in agreement with the measured prolidase activities. The assay of prolidase activities towards Gly-Pro, GlyHyp, Pro-Pro and Pro-Hyp in the erythrocytes of patients, their mother and controls showed that the patients' prolidase (prolidase II) activities towards Gly-Hyp and Pro-Hyp were much lower than those towards Gly-Pro and Pro-Pro, which in turn were very low compared with those of controls. Even in controls, prolidase (prolidase I and II) activities towards Gly-Hyp and Pro-Hyp were extremely low in comparison with those towards Gly-Pro and Pro-Pro. The mother's prolidase activities towards X-Pro and $X$-Hyp were about one half of those of normal controls (tab. 2). These results suggest that the mother's halved activities can hydrolyse all the iminodipeptides

\section{References}

1. Powell, G. F., Rasco, M. A. \& Maniscalco, R. M. (1974) A prolidase deficiency in man with iminopeptiduria. Metabolism 23, 505-513.

2. Jackson, S. H., Dennis, A. W. \& Greenberg, M. (1975) Iminodipeptiduria: A genetic defect in recycling collagen: A method for determining prolidase in erythrocytes. Can. Med. Assoc. J. 113, 759-763.

3. Buist, N. R. M., Strandholm, J. J., Bellinger, J. F. \& Kennaway, N. E. (1972) Further studies on a patient with iminodipeptiduria: A probable case of prolidase deficiency. Metabolism 211, 1113-1124.

4. Umemura, S. (1978) Studies on a patient with iminopeptiduria. II Lack of prolidase in blood cells. Physiol. Chem. Phys. 10, 279-283.

5. Arata, J., Umemura, S., Yamamoto, Y., Hagiyama, M. \& Nohara, N. (1979) Prolidase deficiency; its dermatological manifestations and some additional biochemical studies. Arch. Dermatol. 115, 62-67.

6. Goodman, S. I., Solomons, C. C., Muschenheim, F., McIntyre, C. A., Miles, B. \& O'Brien, D. (1968) A syndrome resembling lathyrism associated with iminodipeptiduria. Am. J. Med. 45, 152-159.

7. Kodama, H., Umemura, S., Shimomura, M., Mizuhara, S., Arata, J., Yamamoto, Y., Yasutake, A. \& Izumiya, N. (1976) Studies on a patient with iminopeptiduria. I Identification of urinary iminopeptides. Physiol. Chem. Phys. 8, 463-473.

8. Mikasa, H., Sasaki, K., Kodama, H., Arata, J. \& Ideda, M. (1984) Isotachophoretic analysis of iminopeptides in the urine of patients with iminopeptiduria. J. Chromatogr. 305, 204-209.

9. Molnár, I. \& Horváth, C. (1977) Separation of amino acids and peptides on non-polar stationary phases by high-performance liquid chromatography. J. Chromatogr. 142, $623-640$

10. Horning, E. C., Carroll, D. I., Dzidic, I., Haegele, K. D., Horning, M. C. \& Stillwell, R. N. (1974) Liquid chromatograph-mass spectrometer-computer analytical systems. A continuous-flow system based on atmospheric pressure ionization mass spectrometry. J. Chromatogr. 99, 13-21. containing a C-terminal proline, which are produced by the metabolism of collagen, so that X-Pro cannot be detected in her urine. However, low prolidase activities towards X-Hyp in the mother and normal volunteers were not sufficient for the hydrolysis of all the endogenous iminodipeptides containing a C-terminal hydroxyproline, so that small amounts of unhydrolysed Gly-Hyp and Pro-Hyp are found in their urines.

This report shows that LC/API-MS (SIM mode) is very suitable for the detection and quantification of urinary peptides, even in very small amounts.

\section{Acknowledgement}

We wish to thank Prof. Dr. Hajime Kodama (Department of Dermatology, Kochi Medical School, Japan) for kindly supplying the urine and blood of patients with prolidase deficiency.

This work was supported in part by a Grant-in-Aid for Scientific Research from the Ministry of Education, Science and Culture of Japan.

11. Kodama, H., Nakamura, H., Sugahara, K. \& Numajiri, Y. (1990) Liquid chromatography-mass spectrometry for the qualitative analyses of iminodipeptides in the urine of patients with prolidase deficiency. J. Chromatogr. 527, 279288.

12. Endo, F., Matsuda, I., Ogata, A. \& Tanaka, S. (1982) Human erythrocyte prolidase and prolidase deficiency. Pediatr. Res. 16, 227-231.

13. Butterworth, J. \& Priestman, D. A. (1985) Presence in human cells and tissues of two prolidases and their alteration in prolidase deficiency. J. Inher. Metab. Dis. 8, 193197.

14. Kodama, H., Ohhashi, T., Ohba, C., Ohno, T., Arata, J., Kubonishi, I. \& Miyoshi, I. (1989) Characteristics and partial purification of prolidase and prolinase from leukocytes of a normal human and a patient with prolidase deficiency. Clin. Chim. Acta 180, 65-72.

15. Ohhashi, T., Ohno. T.. Arata, J., Sugahara, K. \& Kodama, H. (1990) Characterization of prolidase I and II from erythrocytes of a control, a patient with prolidase deficiency and her mother. Clin. Chim. Acta 187, 1-10.

16. Oono, T., Yasutomi, H., Ohhashi, T., Kodama, H. \& Arata, J. (1990) Characterization of fibroblast-derived prolidase. J. Dermatol. Science 1, 319-324.

17. Sakairi, M. \& Kambara, H. (1989) Atmospheric pressure spray ionization for liquid chromatography/mass spectrometry. Anal. Chem. 61, 1159-1164.

18. Chinard, F. P. (1952) Photometric estimation of proline and ornithine. J. Biol. Chem. 199, 91-95.

19. Kodama, H., Mikasa, H., Ohhashi, T., Ohno, T. \& Arata, J. (1988) Biochemical investigations on prolidase and prolinase in erythrocytes from patients with prolidase deficiency. Clin. Chim. Acta 173, 317-324.

Kazunori Sugahara Department of Chemistry Kochi Medical School Kohasu, Oko-cho, Nankoku-shi Kochi, 783, Japan 